\title{
Intrauterine embryo transfer with canine embryos cryopreserved by the slow freezing and the Cryotop method
}

\author{
Tatsuya HORI ${ }^{1) *}$, Hitoshi USHIJIMA ${ }^{2)}$, Taku KIMURA ${ }^{1)}$, Masanori KOBAYASHI ${ }^{1)}$, Eiichi KAWAKAMI ${ }^{1)}$ and \\ Toshihiko TSUTSUI ${ }^{1,3)}$ \\ ${ }^{1)}$ Laboratory of Reproduction, Nippon Veterinary and Life Science University, 1-7-1 Kyonan-cho, Musashino-shi, Tokyo 180-8602, Japan \\ ${ }^{2)}$ Laboratory of Animal Reproduction, Nippon Veterinary and Life Science University, 1-7-1 Kyonan-cho, Musashino-shi, Tokyo \\ 180-8602, Japan \\ 3) International Institute of Small Animal Medicine (Bio Plus), AHB Inc., 3-7-11 Kiba, Koutou-ku, Tokyo 135-0042, Japan
}

(Received 24 January 2016/Accepted 22 March 2016/Published online in J-STAGE 3 April 2016)

ABSTRACT. Canine embryos (8-cell to blastocyst stages) frozen-thawed using the slow-freezing method with glycerol (four recipients) or dimethyl sulfoxide (three recipients) as a cryoprotectant and vitrified-warmed using the Cryotop method (five recipients) were surgically transferred into the unilateral uterine horn of recipient bitches. As a result, the morphology of embryos frozen-thawed using the slowfreezing method was judged to be normal, but no conception occurred in any of the recipient bitches. Two of the five bitches that received transferred embryos (morula to early blastocyst stages) vitrified-warmed using the Cryotop method became pregnant and produced normal pups (1/9 embryos, $11.1 \%$ and $1 / 6$ embryos, $17.0 \%)$. It was concluded that the Cryotop method was more appropriate for canine embryo cryopreservation than the slow-freezing method, which is used for the cryopreservation of embryos of other mammalian species.

KEY WORDS: cryopreservation, Cryotop method, dog, embryo, slow freezing method

doi: 10.1292/jvms.16-0037; J. Vet. Med. Sci. 78(7): 1137-1143, 2016

For the reproduction of assistance dogs, including guide dogs, greater importance is attached to the strain. The cryopreservation of canine embryos is necessary to manage and reproduce excellent gametes on a worldwide scale, and the establishment of techniques for this process is needed. Embryo-freezing techniques are also assumed to be useful for the preservation of gametes of rare dog breeds and valuable dog strains that serve as models for human disease as well as studies on the embryo preservation of endangered wild Canidae [3, 6]. However, although many mammalian species, such as cattle [23], pigs [15], cats [5, 7] and mice [22], have been obtained by the transfer of frozen-thawed embryos, studies on frozen canine embryos lag behind these other studies, and no pup had been obtained by frozen canine embryo transfer (ET) until Abe et al. reported it in 2011 [2]. Few studies on frozen canine embryos have been reported thereafter, and no cryopreservation techniques for canine embryos have been established.

The slow-freezing method has been used for mammalian embryo cryopreservation, in which embryos penetrated using a preservative solution containing a cryoprotectant (glycerol [Gly] or dimethyl sulfoxide [DMSO]) are packed in straws, slowly frozen in a programmed freezer and stored in liquid nitrogen $\left(\mathrm{LN}_{2}\right)$ [17]. The toxicity of cryoprotectants in embryos and the requirement of sufficient time for freezing are

\footnotetext{
* Correspondence to: Hori, T., Laboratory of Reproduction, Nippon Veterinary and Life Science University, 1-7-1 Kyonan-cho, Musashino-shi, Tokyo 180-8602, Japan. e-mail: t-hori@nvlu.ac.jp (C)2016 The Japanese Society of Veterinary Science

This is an open-access article distributed under the terms of the Creative Commons Attribution Non-Commercial No Derivatives (by-nc-nd) License $<$ http://creativecommons.org/licenses/by-nc-nd/4.0/>.
}

problems associated with this method, but the offspring of many animal species have been obtained by ET of frozenthawed embryos prepared using this method [13, 17, 21]. However, there have been no reports concerning dogs, with the exception of one study in which embryos frozen-thawed using the slow-freezing method with Gly as a cryoprotectant were transferred but pregnancy was not achieved [10]. Since the slow-freezing method using other cryoprotectants has not been investigated, the usefulness of this freezing method for the cryopreservation of canine embryos remains unclear.

Another embryo cryopreservation method termed the vitrification method has beem developed. In this method, a smaller amount of a cryoprotectant is used at a higher concentration than that in the abovementioned method, followed by the placement of embryos in $\mathrm{LN}_{2}[9,17]$. This method is useful, because it does not require a specific device, such as a programmed freezer, is less time consuming and has a high survival rate for warmed embryos. Among vitrification methods, the minimum volume cooling (MVC) method is attracting attention [1]. Embryos are sustained in a small volume $(<0.1 \mu l)$ of vitrifying preservative solution containing a cryoprotectant at a high concentration and are stored in $\mathrm{LN}_{2}$. A high embryo survival rate can be achieved after warming, because ice crystal formation does not occur in this method, compared with that in the slow-freezing method. The Cryotop method is an MVC method [4, 11]. Cryopreservation using the Cryotop method has been reported to have favorable results for the cryopreservation of immature mammalian oocytes and porcine embryos that are considered slightly difficult to cryopreserve $[12,20]$, and the only study in which pups were obtained from canine cryopreserved embryos also used the Cryotop method [2]. In this study, the survival rate of frozen canine embryos was high, and a high conception 
rate was achieved after thawed embryos were non-surgically transferred into the uterine horn through the cervical canal using a rigid cystoscope. However, although the use of a rigid cystoscope is favorable because it is less invasive for dogs, everybody cannot use it because it is expensive and requires training to learn the technique. Moreover, the application of this method to small-sized dogs is difficult. In contrast, surgical intrauterine ET does not require a specific device and is applicable to all dogs [18]. However, it is invasive for animals, even though it is applied through a small surgical incision within a short period of time. It is necessary to investigate the influence of this method on pregnancy after the transfer of canine cryopreserved embryos, which are damaged compared with fresh embryos. Thus, the investigation of this method may be clinically valuable.

In this study, using the slow-freezing method with Gly or DMSO as a cryoprotectant and the Cryotop method, canine embryos produced by natural mating in vivo were cryopreserved. Frozen-thawed embryos were surgically transferred into the uterine horn to investigate the possibility of obtaining pups from these embryos. In our previous study [18], bitches that received a surgical intrauterine transfer of fresh embryos in the 8-cell to blastocyst developmental stages became pregnant. Thus, embryos in these stages were cryopreserved in this study.

\section{MATERIALS AND METHODS}

Animals: All animals used in this study were beagles bred at our colony. Fifteen bitches, aged 2-10 years (mean \pm S.E.: $5.3 \pm 0.4$ years), were used as donors, and 12 bitches, aged $2-5$ years (mean \pm S.E.: $3.2 \pm 0.4$ years), were used as recipients. Eight of these 12 recipient bitches were parous. For male dogs, nine dogs, aged 2-8 years (mean \pm S.E.: $5.1 \pm 0.5$ years), with normal fertility were used. These experimental dogs were kept in cages measuring $160 \times 75 \times$ $65 \mathrm{~cm}$ in each two dogs, fed commercial dog food (Health Nutrition, Royal Canin Japon, Inc., Tokyo, Japan) once a day and given drinking water three times daily. Pregnant bitches were kept individually and given food twice from 35 days of gestation. This study was conducted in conformity with the animal study guidelines of Nippon Veterinary and Life Science University.

Estrus and ovulation monitoring: The bitches were observed daily for pudendal enlargement and the presence or absence of vulval bleeding. For hormone measurements, $1 \mathrm{ml}$ of blood was collected from the anterior brachiocephalic vein every other day starting from day 6 of vulval bleeding. Blood samples were centrifuged to separate the serum, and the progesterone $\left(\mathrm{P}_{4}\right)$ levels were measured by fluorescence enzyme immunoassay using an automated fluorescence immunochemistry analyzer (SPOTCHEM VIDAS SV-5010; ARKRAY, Kyoto, Japan). The day on which the $\mathrm{P}_{4}$ level initially reached $4-6 \mathrm{ng} / \mathrm{m} l$ or higher was regarded as the ovulation day $[8,14]$. Donor bitches were mated once at 3-4 days after the estimated ovulation.

Collection methods of embryos: As previously reported [18], embryos were collected from two donor bitches via laparotomy, using the uterine perfusion method without the excision of the uterus at 10-11 days after ovulation. At 8-11 days after ovulation, embryos were collected from another 13 bitches using oviduct perfusion after conventional ovariohysterectomy (OVHX) [18]. After OVHX, the oviducts and uterine horns were separated; using an 18-G non-beveled needle (Terumo Co., Tokyo, Japan), the oviducts were perfused in the descending direction from the abdominal ostium of the oviduct. The uterus was perfused in the ascending direction from the uterine horn near the corpus uteri. The corpora lutea (number of ovulations) were counted in the excised ovaries or in the ovaries seen through a region of the ovarian bursa without fat. For the perfusion solution, Dulbecco's phosphate-buffered saline (PBS, Gibco ${ }^{\circledR}$ ) or TCM199 (Sigma) was used. The perfusate was immediately subjected to the observation of the stage and number of collected embryos under a stereoscopic microscope, immediately followed by embryo cryopreservation. Embryos with abnormal morphology that showed degeneration at this time point were excluded from cryopreservation.

Embryonic Freezing and thawing methods: In the slowfreezing method, $20 \%$ fetal calf serum $\left(\right.$ Gibco $\left.^{\circledR}\right)$-containing PBS (m-PBS) was used as the basic preservative solution for freezing. Embryos were equilibrated in stages with mPBS containing a cryoprotectant at three concentrations. Embryos were first exposed to m-PBS containing 3\% Gly or $0.5 \mathrm{M}$ DMSO for $10 \mathrm{~min}$, followed by exposure to m-PBS containing $6 \%$ Gly or $1.0 \mathrm{M}$ DMSO for $10 \mathrm{~min}$ and then m-PBS containing $10 \%$ Gly or $1.5 \mathrm{M} \mathrm{DMSO}$ for $30 \mathrm{~min}$. The embryos were subsequently filled in a $0.25-\mathrm{m} l$ straw and cooled from room temperature to $-4^{\circ} \mathrm{C}$ at $-2^{\circ} \mathrm{C} / \mathrm{min}$ using a programmed freezer (ET-1, Fujihira Industry Co., Ltd., Tokyo, Japan), followed by ice seeding at $-4^{\circ} \mathrm{C}$. The embryos were then slowly cooled to $-34^{\circ} \mathrm{C}$ at $-0.3^{\circ} \mathrm{C} / \mathrm{min}$, retained at this temperature for $10 \mathrm{~min}$ and stored in $\mathrm{LN}_{2}$. Embryos were thawed by placing the straw in $37^{\circ} \mathrm{C}$ warm water after keeping them frozen for 4-33 days, exposed to m-PBS containing $6 \%$ Gly or $1.0 \mathrm{M} \mathrm{DMSO}$ for $10 \mathrm{~min}$ at $37^{\circ} \mathrm{C}$, followed by exposure to m-PBS containing $3 \%$ Gly or $0.5 \mathrm{M} \mathrm{DMSO}$ for $10 \mathrm{~min}$ and finally placed in m-PBS without cryoprotectants at $37^{\circ} \mathrm{C}$.

In the Cryotop method, embryos were placed on the liquid surface of an equilibrium solution (ES) containing 7.5\% ethylene glycol (EG) and 7.5\% DMSO. The embryos slowly settled to the bottom as they started to shrink due to osmotic pressure differences; they were kept in ES, while they started to swell, and they stopped swelling after 5 min up to a maximum of $15 \mathrm{~min}$. The embryos contained in a minimum volume of ES were then transferred to the liquid surface of a vitrifying preservative solution (VS) containing $15 \%$ EG, $15 \%$ DMSO and $0.5 \mathrm{M}$ sucrose and washed by pipetting while being moved in VS. The embryos were aspirated, placed with a minimum volume of VS on the tip of the Cryotop sheet under a stereoscopic microscope, rapidly placed in $\mathrm{LN}_{2} 1 \mathrm{~min}$ after transfer into VS for vitrification and stored. Embryos used for ET were kept vitrified for 150-332 days. To warm the embryos, the Cryotop sheet was taken out of $\mathrm{LN}_{2}$, and its tip was placed in $1 \mathrm{M}$ sucrose solution (TS) at 
Table 1. Results of embryo collected from 15 donor bitches

\begin{tabular}{|c|c|c|c|c|c|c|c|c|c|c|}
\hline \multirow{2}{*}{$\begin{array}{l}\text { Cryopreservation } \\
\text { method }\end{array}$} & \multirow{2}{*}{$\begin{array}{c}\text { Donor } \\
\text { bitch No. }\end{array}$} & \multirow{2}{*}{$\begin{array}{c}\text { Age } \\
\text { (years) }\end{array}$} & \multirow{2}{*}{$\begin{array}{c}\text { Body } \\
\text { weight } \\
(\mathrm{kg})\end{array}$} & \multirow{2}{*}{$\begin{array}{c}\text { Male } \\
\text { dog } \\
\text { No. }\end{array}$} & \multirow{2}{*}{$\begin{array}{c}\text { Days from } \\
\text { ovulation to } \\
\text { embryo recovery }\end{array}$} & \multicolumn{2}{|c|}{ No. of CL } & \multirow{2}{*}{$\begin{array}{c}\text { Stage of recovered } \\
\text { embryo }^{\text {a) }} \\
\text { (Number of embryos) }\end{array}$} & \multirow{2}{*}{$\begin{array}{l}\text { Site of embryo } \\
\text { recovery }\end{array}$} & \multirow{2}{*}{$\begin{array}{c}\text { Recovery rate } \\
(\%)\end{array}$} \\
\hline & & & & & & $\mathrm{L}$ & $\mathrm{R}$ & & & \\
\hline \multirow{5}{*}{$\begin{array}{l}\text { Slow Freezing } \\
\text { (glycerol) }\end{array}$} & D1 & 9.6 & 7.5 & M1 & 9 & 5 & $3^{b)}$ & $M(5)$ & Oviduct & 100 \\
\hline & D2 & 5.3 & 9.0 & M2 & 9 & $6^{\text {b) }}$ & 7 & $\begin{array}{l}\mathrm{M}(6) \\
\mathrm{CM}(1)\end{array}$ & $\begin{array}{l}\text { Oviduct } \\
\text { Uterus }\end{array}$ & 100 \\
\hline & D3 & 4.3 & 10.0 & M3 & 10 & 4 & 3 & $\mathrm{M}(2)$ & Uterus & $28.6^{\mathrm{d})}$ \\
\hline & D4 & 5.5 & 12.0 & M3 & 11 & 2 & 5 & $\mathrm{~B}(6)$ & Uterus & $85.7^{\text {d) }}$ \\
\hline & D5 & 4.4 & 10.0 & M3 & 11 & 2 & 6 & $\begin{array}{l}M(1) \\
B(4)\end{array}$ & $\begin{array}{l}\text { Oviduct } \\
\text { Uterus }\end{array}$ & 62.5 \\
\hline \multirow{3}{*}{$\begin{array}{l}\text { Slow Freezing } \\
\text { (DMSO) }\end{array}$} & D6 & 4.7 & 11.5 & M4 & 8 & 10 & $-c)$ & 8-cell (8), Deg (2) & Oviduct & 100 \\
\hline & D7 & 5.5 & 13.0 & M2 & 8 & 12 & $-c)$ & 8-cell (11), Deg (1) & Oviduct & 100 \\
\hline & D8 & 7.9 & 12.5 & M5 & 9 & $-c)$ & 9 & $\mathrm{M}(8)$ & Oviduct & 88.9 \\
\hline \multirow{7}{*}{ Cryotop } & D9 & 4.6 & 8.2 & M6 & 8 & 2 & 4 & 8-cell (3), Deg (1) & Oviduct & 67.0 \\
\hline & D10 & 5.8 & 7.2 & M7 & 9 & 7 & 2 & $\begin{array}{l}8 \text {-cell (3), 16-cell (3) } \\
\operatorname{Deg}(3)\end{array}$ & Oviduct & 100 \\
\hline & D11 & 2.1 & 9.4 & M8 & 9 & 6 & 2 & M (5), Deg (3) & Oviduct & 100 \\
\hline & D12 & 5.3 & 9.4 & M9 & 9 & 6 & $-c)$ & $\mathrm{CM}(3)$ & Uterus & 50.0 \\
\hline & D13 & 4.6 & 9.3 & M7 & 10 & 4 & 4 & 8-cell (7), Deg (1) & Oviduct & 88.0 \\
\hline & D14 & 6.0 & 7.2 & M7 & 10 & 2 & 4 & $\mathrm{CM}(1), \mathrm{EB}(5)$ & Uterus & 100 \\
\hline & D15 & 4.7 & 9.8 & M7 & 11 & 5 & 3 & $M(8)$ & Oviduct/Uterus & 100 \\
\hline \multirow{2}{*}{ Mean \pm S.E. } & & 5.3 & 9.7 & & & & & & & 88.7 \\
\hline & & 0.4 & 0.5 & & & & & & & 4.7 \\
\hline
\end{tabular}

a) M: morula, CM: compacted morula, EB: early blastocyst, B: blastocyst, Deg: degenerated ova. b) Not recovery c) Ovary had already been removed d) Uterine flushing by laparotomy.

$37^{\circ} \mathrm{C}$ and slowly moved into TS until the embryos detached from the sheet. The embryos were collected $60 \mathrm{sec}$ after they were transferred into TS, placed on the bottom of a solution containing $0.5 \mathrm{M}$ sucrose (DS) and held for $3 \mathrm{~min}$. The embryos were then transferred to the bottom of a washing solution (WS) and held for $5 \mathrm{~min}$, followed by transfer to the surface of new WS.

After thawing or warming, only embryos estimated to be morphologically normal by macroscopic examination under an inverted microscope were selected and held in each solution (m-PBS or WS) at $37^{\circ} \mathrm{C}$ until transfer.

Embryo transfer: The transfer day was set so as to adjust the difference between the time to collection of embryos after ovulation in the donor and the time to transfer after ovulation in the recipient to \pm 1 day. To shorten the time to ET from thawing, embryo thawing was started corresponding to the state of surgery. As a rule, embryos collected from one donor were transferred to one recipient, but in some cases, embryos collected from multiple bitches with embryos in the corresponding developmental stages were transferred to one recipient bitch. Embryos were transferred using the previously reported surgical intrauterine transfer method [19]. Laparotomy was applied to a recipient bitch, and the uterine horn was exposed. An 18-G injection needle was penetrated into the uterine lumen, a glass capillary containing embryos was inserted with a small volume of solution into this hole, and embryos were slowly infused into the uterine horn. The insertion site was immediately sutured, and the abdomen was closed.

Pregnancy diagnosis: Pregnancy was evaluated at 25-30 days after ovulation in the recipient using an ultrasonographic imaging diagnosis system (ECHOVISOIN SSD-500EV, Aloka Medical, Ltd., Tokyo, Japan). Pregnant bitches were observed every 5 days after pregnancy determination to confirm normal embryonic development until delivery.

DNA test: When pups were obtained by the transfer of frozen embryos derived from multiple donor bitches, a parentage diagnosis was made by DNA testing. The canine oral mucosa to be examined by the DNA test (paternal and maternal dogs of the transferred embryos and pups) was collected using sterile swabs, and the sequences of DNA markers were collated to diagnose parentage by a DNA testing institution, Genetic Technologies. Eleven DNA markers were used including PEZ01, FHC2054, FHC2010, PEZ05, PEZ20, PEZ12, PEZ03, PEZ06, PEZ08, FHC2079 and PEZ16.

\section{RESULTS}

The results of embryo collection from 15 donor bitches are shown in Table 1. The embryo recovery rate was low in the one of two bitches in whom the uterine perfusion method was used $(28.6$ and $85.7 \%)$, but the recovery rate was $50 \%-100 \%$ (mean, $88.7 \pm 4.7 \%$ ) in the 13 bitches in whom the embryos were collected after OVHX. A total of 100 embryos in various developmental stages were collected from 15 donor bitches. Excluding 11 embryos assumed to be degenerated (11.0\%), 89 embryos in the 8-cell to blastocyst stages were cryopreserved using the slow-freezing $(n=51)$ or Cryotop method $(n=38)$.

The ET conception results with cryopreserved embryos 
are shown in Tables 2 and 3. Four of the 12 recipients received transferred embryos collected from two donors. All of the embryonic morphology was judged to be normal in frozen-thawed embryos prepared using the slow-freezing method with Gly or DMSO as a cryoprotectant, but no conception ocurrred in any of the bitches that received these embryos. On the other hand, vitrified-warmed embryos prepared using the Cryotop method (Fig. 1) were transferred to five bitches, and two of them became pregnant. In one of them, Bitch No. R10, delivery signs and labor started at 65 days after ovulation, but no fetus was delivered. Since the fetal heart rate decreased to about 100 beats/min on echocardiography, cesarean section was immediately performed. All pups were male, no external abnormality was noted, and they developed normally.

One of the two bitches (Bitch No. R10) that became pregnant received embryos collected from two donor bitches. Thus, the donors, pup and the paternal dogs were subjected to DNA testing. As shown in Table 4, D14 and M9 were the parents of the pup.

\section{DISCUSSION}

When canine embryos were vitrified using the Cryotop method and surgically transferred into the uterine horn after warming, the conception rate was $40 \%$ and normal pups were obtained. This conception rate was slightly lower than that reported in the study by Abe et al., $(55.6 \%$; delivery rate, $44.5 \%$ ) [2], in which embryos were similarly prepared using the Cryotop method and non-surgically transferred into the uterus transcervically using a cystoscope in nine female Labrador retrievers, and five became pregnant. In our study, 35 embryos were transferred, and two pups were born; this rate $(5.7 \%)$ was slightly lower than that reported by Abe et al. $(9.1 \%, 77$ embryos were transferred, and seven pups were born) [2]. This difference may have been more likely due to the difference in the transfer method rather than in the dog breed. To reliably transfer embryos, a less invasive nonsurgical method may be appropriate, but transcervical intrauterine transfer using a cystoscope may be more difficult for small-sized dogs than for large-sized dogs. Thus, it is worth investigating surgical intrauterine ET as the transfer method of frozen embryos. Our study clarified that normal pups can be obtained by surgically transferring frozen canine embryos into the uterine horn.

We used embryos in the 8-cell to blastocyst stages for the Cryotop method, but only bitches that received embryos in the morula to early blastocyst stages became pregnant. None of the bitches that received 8- or 16-cell embryos became pregnant. This result is inconsistent with the findings reported by Abe et al. [2], in which bitches that received frozen 8- and 16-cell embryos became pregnant but those receiving morulas did not. They subjected frozen embryos to fluorescent staining and observed that the survival rate of embryos transferred after the morula stage was low. It is generally known that developmental embryos are more suitable for freezing and more easily frozen than early stage embryos, and blastocysts are considered most appropriate

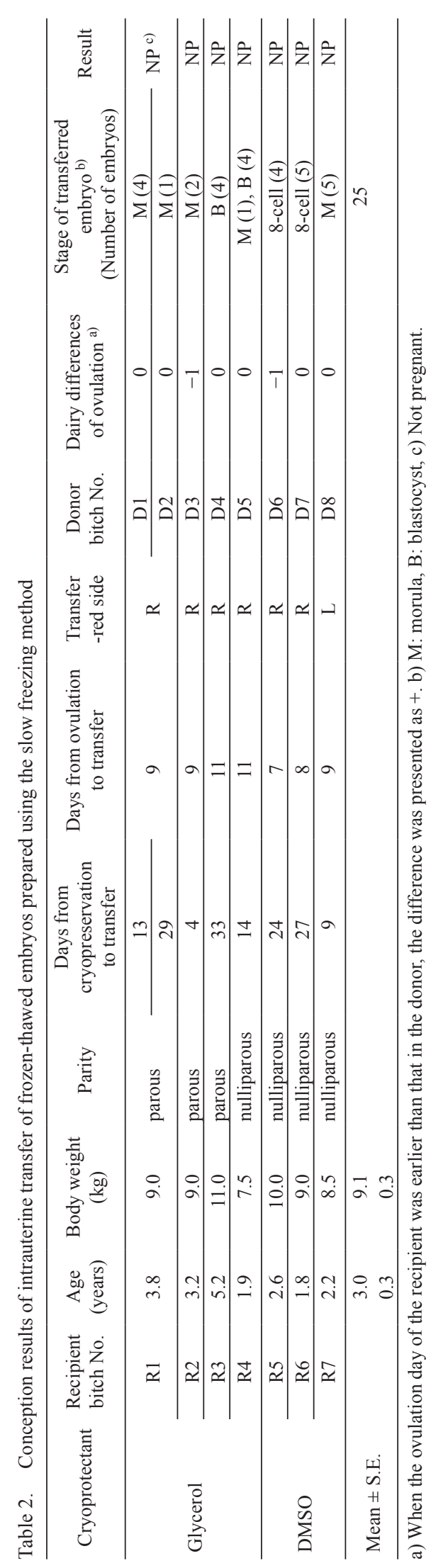



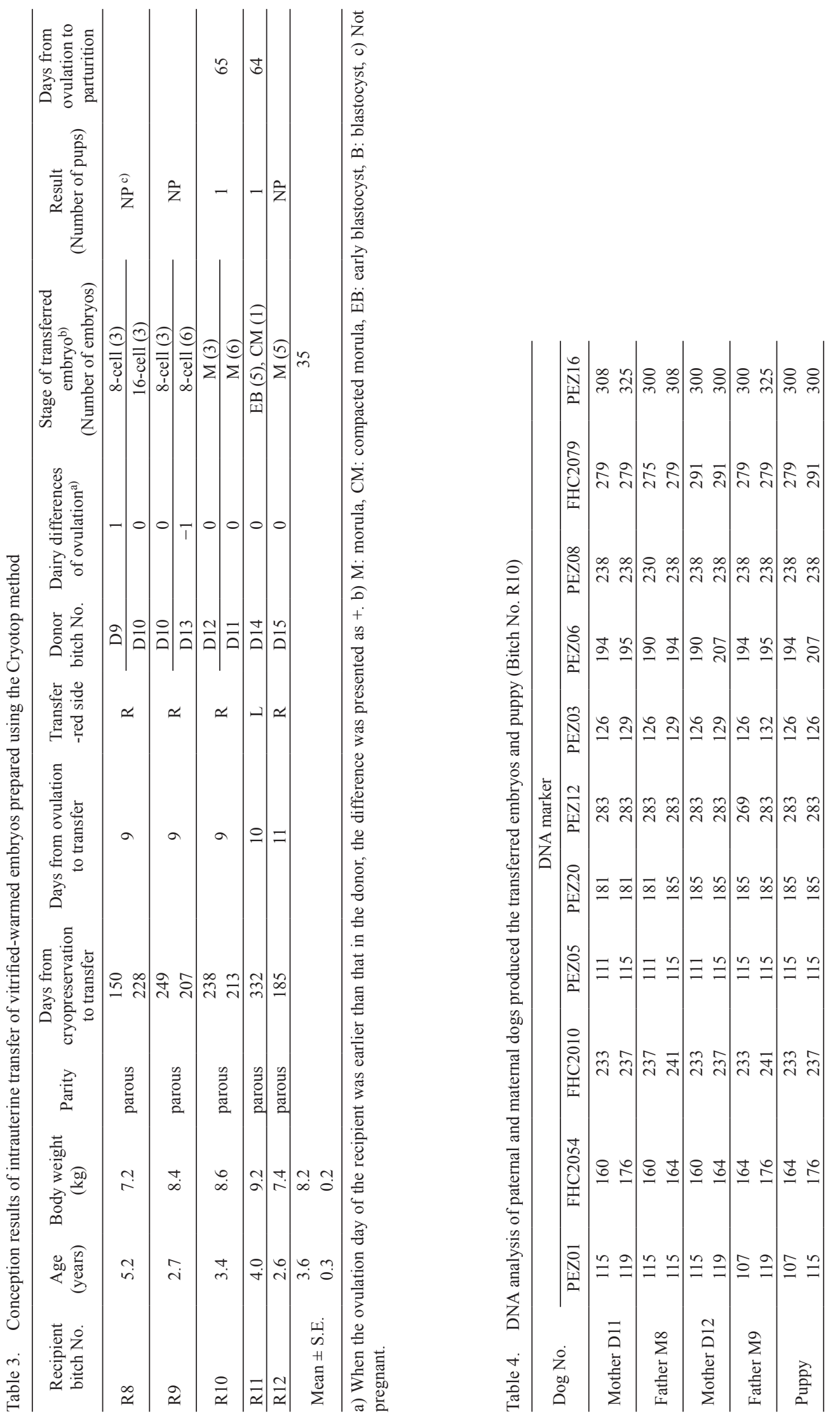


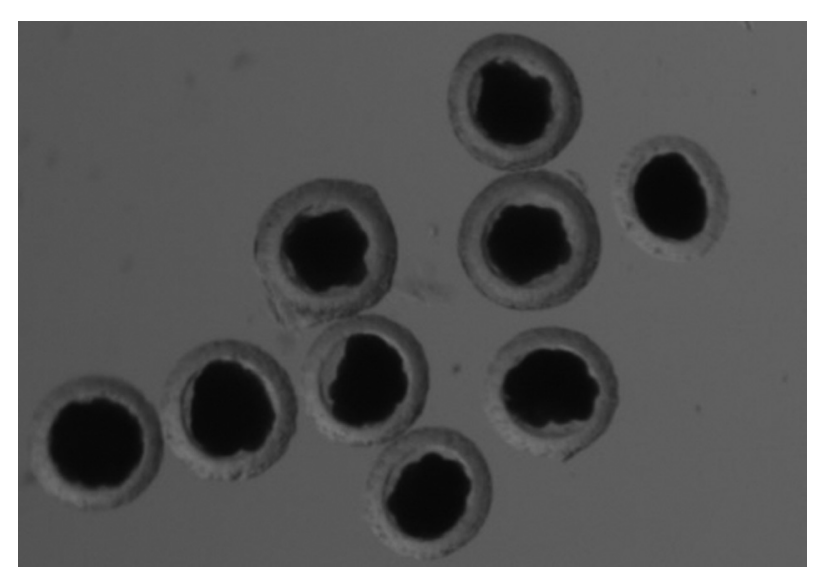

Fig. 1. Embryos of morula stage after vitrified-warmed using the Cryotop method. These embryos were transferred to Bitch No. R10.

for cryopreservation. In addition, we previously reported a study on the surgical intrauterine transfer of fresh canine embryos, in which 16-cell to blastocysts stage embryos were appropriate for transfer [18]. Furthermore, expanded blastocysts are considered slightly difficult to handle in vitro, because trophoblasts may shrink away from the zona pellucida in culture medium [16]. Therefore, embryos in the morula to early blastocyst stages may be appropriate for the cryopreservation of canine embryos. To successfully transfer frozen embryos, the timing of transfer may also be important. Studies on fresh ET reported that transfer within a \pm 1-day difference between the time to embryo collection after ovulation in the donor and the time to ET after ovulation in the recipient is appropriate [18]. In the study reported by Abe et al. [2], the difference in the time after the luteinizing hormone (LH) surge between the donor and recipient bitches was 1-4 days in all bitches and 1-2 days in pregnant bitches, indicating a slight difference in LH levels between the two groups. In our study, the difference in the time to embryo collection after ovulation in the donor and time to ET after ovulation in the recipient was \pm 0 days in all bitches, including those that became pregnant, suggesting that the same timing between the donor and recipient bitches was necessary to successfully transfer embryos. However, cryopreserved embryos were damaged to some extent, and they needed some time to adapt to the uterine environment in the recipient bitch. Accordingly, it may be better to set the timing of transfer a little earlier in the recipient bitch, rather than $\mathrm{a} \pm 0$-day difference between the donor and recipient bitches, but we could not clarify this because we did not perform the transfer of cryopreserved morulas under this condition.

Parent analysis was performed using 11 DNA markers. The number of DNA markers was less than that used by Abe et al. (23 microsatellite markers) [2], but it was sufficient to make a judgment. Since embryos were collected in vivo, it is not possible to collect many embryos from one animal. However, the success rate of ET rises as the number of transferred embryos increases. Thus, we transferred embryos collected from different bitches. The maternal and paternal dogs could be identified by parentage analysis using DNA markers, demonstrating that there is no problem with transferred embryos collected from multiple dogs.

Frozen canine embryos prepared by the slow-freezing method [17] with DMSO or Gly as a cryoprotectant, which is used for the embryos of many mammalian species, were similarly surgically transferred into the uterine horn. No conception was obtained, and this result was consistent with the findings reported in the study by Kim et al. [10], in which canine embryos frozen-thawed and prepared by the slowfreezing method with Gly were transferred. These findings suggested that the cryopreservation of canine embryos using the slow-freezing method is difficult with any cryoprotectant, although this method is generally used for other animal species. For this reason, the accumulation of phospholipids constituting the cell membrane and neutral fat in egg yolk that serves as an energy source is more abundant in many canine embryos than other mammalian embryos. These lipids are considered to be destroyed by in vitro manipulation due to the low-temperature sensitization of embryos, which interferes with embryonic development, and the high ratios of triglycerides and fatty acids constituting fat. These embryonic characteristics may be the reason for the inability to freeze embryos using the slow-freezing method. Regarding this point, Ushijima et al. [19] reported that when porcine morulas, known to contain abundant lipids in egg yolk, similar to canine embryos, were isolated by centrifugation and preserved by vitrification after removing the fat in the egg yolk, the embryo survival rate after warming was significantly improved to $95 \%$ (35/37) compared with that after the conventional vitrification method (24/42, 57\%). A high conception rate was achieved when these embryos were transferred, suggesting that a high conception rate can be obtained in bitches by applying this method to removing the fat from the egg yolk using a micromanipulator and increasing the resistance of embryos to freezing, followed by cryopreservation using the Cryotop method. This remains to be further investigated.

It was concluded that the Cryotop method is more appropriate for canine embryo cryopreservation than the slowfreezing method used for the embryos of other mammalian species. Regarding the embryo developmental stage suitable for cryopreservation, the morula to early blastocyst stages may be appropriate.

ACKNOWLEDGMENTS. This work was supported by JSPS KAKENHI Grant Number 18658128 and 25450453.

\section{REFERENCES}

1. Abdalla, H., Shimoda, M., Hara, H., Morita, H., Kuwayama, M., Hirabayashi, M. and Hochi, S. 2010. Vitrification of ICSI- and IVF-derived bovine blastocysts by minimum volume cooling procedure: effect of developmental stage and age. Theriogenology 74: 1028-1035. [Medline] [CrossRef]

2. Abe, Y., Suwa, Y., Asano, T., Ueta, Y. Y., Kobayashi, N., Ohshima, N., Shirasuna, S., Abdel-Ghani, M. A., Oi, M., Kobayashi, 
Y., Miyoshi, M., Miyahara, K. and Suzuki, H. 2011. Cryopreservation of canine embryos. Biol. Reprod. 84: 363-368. [Medline] [CrossRef]

3. Boutelle, S., Lenahan, K., Krisher, R., Bauman, K. L., Asa, C. S. and Silber, S. 2011. Vitrification of oocytes from endangered Mexican gray wolves (Canis lupus baileyi). Theriogenology $\mathbf{7 5}$ : 647-654. [Medline] [CrossRef]

4. Cobo, A., Bellver, J., Domingo, J., Pérez, S., Crespo, J., Pellicer, A. and Remohí, J. 2008. New options in assisted reproduction technology: the Cryotop method of oocyte vitrification. Reprod. Biomed. Online 17: 68-72. [Medline] [CrossRef]

5. Dresser, B. L., Gelwicks, E. J., Wachs, K. B. and Keller, G. L. 1988. First successful transfer of cryopreserved feline (Felis catus) embryos resulting in live offspring. J. Exp. Zool. 246: 180-186. [Medline] [CrossRef]

6. Guaitolini, C. R., Taffarel, M. O., Teixeira, N. S., Sudano, M. J., Freitas, P. M., Lopes, M. D., Landin-Alvarenga, F. C., de Oliveira, C. A. and Luz, M. R. 2012. Post-thaw viability of in vivo-produced canine blastocysts cryopreserved by slow freezing. Theriogenology 78: 576-582. [Medline] [CrossRef]

7. Gómez, M. C., Pope, E., Harris, R., Mikota, S. and Dresser, B. L. 2003. Development of in vitro matured, in vitro fertilized domestic cat embryos following cryopreservation, culture and transfer. Theriogenology 60: 239-251. [Medline] [CrossRef]

8. Hase, M., Hori, T., Kawakami, E. and Tsutsui, T. 2000. Plasma $\mathrm{LH}$ and progesterone levels before and after ovulation and observation of ovarian follicles by ultrasonographic diagnosis system in dogs. J. Vet. Med. Sci. 62: 243-248. [Medline] [CrossRef]

9. Kasai, M. and Mukaida, T. 2004. Cryopreservation of animal and human embryos by vitrification. Reprod. Biomed. Online 9: 164-170. [Medline] [CrossRef]

10. Kim, Y. J., Kim, B. J. and You, I. J. 2002. Embryo transfer with frozen embryos in the dog. J. Vet. Clin. 19: 73-79.

11. Kuwayama, M. 2007. Highly efficient vitrification for cryopreservation of human oocytes and embryos: the Cryotop method. Theriogenology 67: 73-80. [Medline] [CrossRef]

12. Liang, Y., Rakwongrit, D., Phermthai, T., Somfai, T., Nagai, T. and Parnpai, R. 2012. Cryopreservation of immature buffalo oocytes: effects of cytochalasin B pretreatment on the efficiency of cryotop and solid surface vitrification methods. Anim. Sci. J. 83: 630-638. [Medline] [CrossRef]

13. Martínez, A. G. and Matkovic, M. 1998. Cryopreservation of ovine embryos: slow freezing and vitrification. Theriogenology 49: 1039-1049. [Medline] [CrossRef]

14. Moxon, R., Copley, D. and England, G. C. 2010. Technical and financial evaluation of assays for progesterone in canine practice in the UK. Vet. Rec. 167: 528-531. [Medline] [CrossRef]

15. Nagashima, H., Hiruma, K., Saito, H., Tomii, R., Ueno, S., Nakayama, N., Matsunari, H. and Kurome, M. 2007. Production of live piglets following cryopreservation of embryos derived from in vitro-matured oocytes. Biol. Reprod. 76: 900-905. [Medline] [CrossRef]

16. Renton, J. P., Boyd, J. S., Eckersall, P. D., Ferguson, J. M., Harvey, M. J. A., Mullaney, J. and Perry, B. 1991. Ovulation, fertilization and early embryonic development in the bitch (Canis familiaris). J. Reprod. Fertil. 93: 221-231. [Medline] [CrossRef]

17. Saragusty, J. and Arav, A. 2011. Current progress in oocyte and embryo cryopreservation by slow freezing and vitrification. Reproduction 141: 1-19. [Medline] [CrossRef]

18. Tsutsui, T., Hori, T., Okazaki, H., Tanaka, A., Shiono, M., Yokosuka, M. and Kawakami, E. 2001. Transfer of canine embryos at various developmental stages recovered by hysterectomy or surgical uterine flushing. J. Vet. Med. Sci. 63: 401-405. [Medline] [CrossRef]

19. Ushijima, H., Yoshioka, H., Esaki, R., Takahashi, K., Kuwayama, M., Nakane, T. and Nagashima, H. 2004. Improved survival of vitrified in vivo-derived porcine embryos. J. Reprod. Dev. 50: 481-486. [Medline] [CrossRef]

20. Vallorani, C., Spinaci, M., Bucci, D., Porcu, E., Tamanini, C. and Galeati, G. 2012. Pig oocyte vitrification by Cryotop method and the activation of the apoptotic cascade. Anim. Reprod. Sci. 135: 68-74. [Medline] [CrossRef]

21. Van Wagtendonk-De Leeuw, A. M., Den Daas, J. H., Kruip, T. A. and Rall, W. F. 1995. Comparison of the efficacy of conventional slow freezing and rapid cryopreservation methods for bovine embryos. Cryobiology 32: 157-167. [Medline] [CrossRef]

22. Zander-Fox, D., Lane, M. and Hamilton, H. 2013. Slow freezing and vitrification of mouse morula and early blastocysts. J. Assist. Reprod. Genet. 30: 1091-1098. [Medline] [CrossRef]

23. Zhang, L., Barry, D. M., Denniston, R. S., Bunch, T. D. and Godke, R. A. 1993. Birth of live calves after transfer of frozenthawed bovine embryos fertilised in vitro. Vet. Rec. 132: 247249. [Medline] [CrossRef] 